NASA Technical Memorandum 106187

AIAA-93-2252

\title{
High Reynolds Number and Turbulence Effects on Aerodynamics and Heat Transfer in a Turbine Cascade
}

Frederick C. Yeh, Steven A. Hippensteele, G. James Van Fossen, Philip E. Poinsatte, and Ali Ameri

Lewis Research Center

Cleveland, Ohio

Prepared for the

29th Joint Propulsion Conference and Exhibit

cosponsored by the AIAA, SAE, ASME, and ASEE

Monterey, California, June 28-30, 1993 


\title{
HIGH REYNOLDS NUMBER AND TURBULENCE EFFECTS ON AERODYNAMICS
}

\author{
AND HEAT TRANSFER IN A TURBINE CASCADE \\ Frederick C. Yeh, Steven A. Hippensteele, G. James VanFossen, \\ Philip E. Poinsatte, and Ali Ameri \\ National Aeronautics and Space Administration \\ Lewis Research Center \\ Cleveland, Ohio 44135
}

\section{$\underline{\text { Abstract }}$}

Experimental data on pressure distribution and heat transfer on a turbine airfoil were obtained over a range of Reynolds numbers from 0.75 to $7.0 \times 10^{6}$ and a range of turbulence intensities from 1.8 to about 15 percent. The purpose of this study was to obtain fundamental heat transfer and pressure distribution data over a wide range of high Reynolds numbers and to extend the heat transfer data base to include the range of Reynolds numbers encountered in the Space Shuttle main engine (SSME) turbopump turbines. Specifically, the study aimed to determine (1) the effect of Reynolds number on heat transfer, (2) the effect of upstream turbulence on heat transfer and pressure distribution, and (3) the relationship between heat transfer at high Reynolds numbers and the current data base. The results of this study indicated that Reynolds number and turbulence intensity have a large effect on both the transition from laminar to turbulent flow and the resulting heat transfer. For a given turbulence intensity, heat transfer for all Reynolds numbers at the leading edge can be correlated with the Frossling number developed for lower Reynolds numbers. For a given turbulence intensity, heat transfer for the airfoil surfaces downstream of the leading edge can be approximately correlated with a dimensionless parameter. Comparison of the experimental results were also made with a numerical solution from a twodimensional Navier-Stokes code.

\section{Nomenclature}

A

B curve-fitting polynomial coefficient

C chord length, $\mathrm{ft}$

d leading edge diameter, $\mathrm{ft}$

E mean voltage, volts

$\operatorname{Fr}(0)$ Frossling number at stagnation point, $\mathrm{Nu}_{\mathrm{d}} /\left(\mathrm{Re}_{\text {inlet }}\right)^{0.5}$

$\mathrm{h}$ k

$\mathrm{L}$

$\mathrm{Nu} \quad$ Nusselt number, $\mathrm{h} \mathrm{d} / \mathrm{k}$

$\mathrm{P} \quad$ pressure, psia

Pr Prandtl number

Q

$\mathrm{Re}_{\text {exit }}$

$\mathrm{Re}_{\text {inlet }}$

r

$\mathrm{S}$

$\mathrm{s}$

$\mathrm{T}$

$\mathrm{Tu}$

$\mathrm{V}$

W

$\theta$

$\Lambda_{\mathrm{x}}$

$\mu$

$\rho$

Subscripts:

$0,1,2,3,4$

c

d

g

i surface, in.

heat flow rate, Btu/hr airfoil exit conditions

blade pitch, in.

temperature, ${ }^{\circ} \mathrm{R}$

fluid velocity, $\mathrm{ft} / \mathrm{sec}$

flow rate, $\mathrm{lb} / \mathrm{sec}$

flow angle, rad or deg

fluid density, $\mathrm{lb} / \mathrm{ft}^{3}$

chord length

leading edge diameter

gas

input thermal conductivity of air, $\approx 0.0147 \mathrm{Btu} /\left(\mathrm{hr} / \mathrm{ft} /{ }^{\circ} \mathrm{F}\right)$

total length of airfoil pressure or suction

Reynolds number, based on axial chord and

Reynolds number, based on leading edge diameter and inlet conditions

recovery factor, $(\mathrm{Pr})^{1 / 3} \approx 0.89$

distance along airfoil pressure or suction surface from airfoil stagnation point, in.

turbulence intensity, percent

longitudinal integral length scale

dynamic viscosity, lb/ft-sec

curve-fitting polynomial coefficients

\footnotetext{
"Resident Research Associate, NASA Lewis Research Center.
} 


$\begin{array}{ll}\text { in } & \text { inlet } \\ \text { L } & \text { loss } \\ \text { LC } & \text { liquid crystal } \\ \text { R } & \text { recovery } \\ \text { s } & \text { surface distance from airfoil stagnation point } \\ \text { st } & \text { static } \\ \text { t } & \text { total } \\ \text { Superscript: } \\ \text { fluctuating velocity component } \\ \end{array}$

The turbines used in the Space Shuttle main engine (SSME) run at very high pressures and Reynolds numbers. At these extreme conditions, the heat transfer rates to the turbine airfoils are expected to be significantly higher than those of current aeropropulsion turbines. A detailed knowledge of heat transfer at these extreme conditions is necessary to predict airfoil surface temperatures and satisfy life goals.

A large body of flow and heat transfer data over airfoils for current aeropropulsion turbines at lower Reynolds numbers on the order of $10^{6}$ is available in the literature. However, very little information is available for the range of higher Reynolds numbers found in the SSME turbopump turbines.

A Variable Reynolds Number Heat Transfer Cascade Facility was constructed at the NASA Lewis Research Center. Its purpose was to conduct a fundamental study on heat transfer at Reynolds numbers ranging from current aeropropulsion gas turbine levels to those found in the SSME turbopump turbines. The effect of free-stream turbulence on heat transfer and the relationship between heat transfer data at high Reynolds numbers and the current data base was investigated. Turbulence-generating grids were used to vary the turbulence intensity levels in the test section. The facility is capable of operating over a range of Reynolds numbers from 0.75 to over $7.0 \times 10^{6}$ (based on axial chord and airfoil exit conditions) and a range of turbulence intensities from 1.8 to about 15 percent.

Heat transfer and airfoil pressure distribution data were obtained at Reynolds numbers of $0.75,1.5,3.0,5.0$, and $7.0 \times 10^{6}$. The measured turbulence intensity levels ranged from 1.8 percent at a Reynolds number of $7.0 \times 10^{6}$ with no grid (clear tunnel case) to 15.1 percent at a Reynolds number of $0.75 \times 10^{6}$ with $1 / 4$-in. grid. Preliminary results from this facility were reported in Schobeiri, McFarland, and Yeh. ${ }^{1}$ This paper presents the latest heat transfer and pressure distribution results from this facility. Experimental heat transfer data are also compared with a numerical solution from the TRAFC2D ${ }^{2}$ code.

\section{$\underline{\text { Facility }}$}

\section{General Description}

Figure 1 is an illustration of the test facility, including a cutaway view of the test section. Compressed air at 40 psig and ambient temperature flows through an 18-in.-diameter pipe which houses screens and perforated plates for flow conditioning. The maximum flow rate of the facility is about $38 \mathrm{lb} / \mathrm{sec}$; the air flow exits to the laboratory exhaust system at 1.93 psia. Upstream of the test section, boundary layer air is bled from four sides to provide a uniform velocity profile at the test section entrance. The main air, flow as well as each individual bleed air flow, is measured with a sharpedged orifice.

\section{$\underline{\text { Test Section }}$}

The test section with the cover plate removed is shown in Fig. 2. Visible in this photograph are the airfoil, the contoured sidewalls, the hot film anemometer probe, the inlet and exit flow angle measurement probes, and the Pitot static probe. A turbulence grid, not visible, is located behind the grid cover. Two turbulence grids were used to vary the turbulence intensity in the test section. The grids were of the square-mesh, bi-plane type with square bars, one having $1 / 8$-in. square bars and the other having 1/4-in. square bars. Tests were also conducted using a clear tunnel only (no grid). The ratio of mesh-to-bar width spacing was 4.5 , giving a 60 -percent open flow area. The traversing anemometer probe, mounted on the test section, is located 3.6 leading edge diameters (6.19 in.) downstream from the grid and 0.77 diameter $(1.31$ in.) in front of the airfoil leading edge. The anemometer probe was used to survey the turbulence intensity in the pitchwise direction.

\section{$\underline{\text { Airfoil }}$}

The airfoil used in these tests has an axial chord of 8.5 in., an actual chord of 11.09 in., a span of 8.5 in., a solidity of 1.32 , a camber angle of $51.7^{\circ}$, and a twodimensional, constant-section vane to provide a uniform flow field. Coordinates of the airfoil and other geometric information are given in Schobeiri, McFarland, and Yeh. ${ }^{1}$ Two airfoils were fabricated: one was used for pressure distribution tests and the other for heat transfer tests. The pressure distribution airfoil is shown in the photograph of Fig. 3. Of the 90 pressure taps on the airfoil, 52 were located at the midspan, and 19 each were located at the hub and tip sections to record any threedimensionality of the flow field around the airfoil. 
The airfoil used for heat transfer tests is shown in Fig. 4. It is overlayed with a thin (0.001-in.) Inconel sheet. Passing an electric current through the Inconel sheet gave a constant heat flux boundary condition. The Inconel sheet was first coated with black paint, then sprayed with a liquid crystal and clear binder mixture. Grid lines were drawn on the airfoil surface to locate the temperature field in the data reduction process. White dots were added as an aid to locate the temperatures indicated by the liquid crystals. Details on the use of the liquid crystal technique on airfoils are given by Hippensteele, Russell, and Torres. ${ }^{3,4}$ A thermocouple was also installed on the airfoil to verify the temperature on the Inconel sheet beneath the liquid crystal coating.

\section{$\underline{\text { Test Procedure }}$}

The Reynolds numbers were obtained by varying the inlet flow rate while keeping the inlet pressure approximately constant. Turbulence intensity measurements were obtained by using a constant temperature hot film anemometer, which was installed in a traversing actuator on top of the test section to survey the flow channel in a pitchwise direction at midspan. Heat transfer tests were conducted for Reynolds numbers of $0.75,1.5,3.0,5.0$, and $7.0 \times 10^{6}$. The inlet Mach numbers ranged from 0.027 to 0.27 ; exit Mach numbers ranged from 0.058 to 0.71 .

Data for turbulence intensity, pressure distribution (using the pressure distribution airfoil), and heat transfer (using the heat transfer airfoil) were recorded at Reynolds numbers of $0.75,1.5,3.0,5.0$, and $7.0 \times 10^{6}$. The first series of tests were conducted with a clear tunnel (no turbulence grid installed); the second series used the 1/8-in. grid; and the last series used the 1/4-in. grid.

\section{Data Reduction Procedure}

\section{Heat Transfer}

Surface heat transfer coefficients were obtained from the energy balance

$$
\mathrm{h}=\frac{\mathrm{Q}_{\mathrm{i}}-\mathrm{Q}_{\mathrm{L}}}{\mathrm{A}\left(\mathrm{T}_{\mathrm{LC}}-\mathrm{T}_{\mathrm{R}}\right)}
$$

where the local heat transfer coefficient $\mathrm{h}$ was calculated at the location of the calibrated color band (an isotherm which, in this case, also represents a uniform heat transfer coefficient). The heat energy $Q_{i}$ supplied to the Inconel heater sheet was calculated from the measured voltage across the sheet and the current through a shunt resistor in series with the sheet. The heat loss $\mathrm{Q}_{\mathrm{L}}$ was the calculated radiation loss from the surface. The very low thermal conductivity material used for the airfoil makes interior heat conduction loss negligible, and thus it is neglected. The area $\mathbf{A}$ was the measured area of the Inconel heater sheet. The temperature of the test surface $\mathrm{T}_{\mathrm{LC}}$ was the calibrated liquid crystal temperature. The local recovery temperature $T_{R}$ of the free-stream air around the airfoil was calculated as

$$
\mathrm{T}_{\mathrm{R}}=\mathrm{T}_{\mathrm{st}}+\mathrm{r}\left(\mathrm{T}_{\mathrm{t}}-\mathrm{T}_{\mathrm{st}}\right)
$$

where $T_{\text {st }}$ and $T_{t}$ are the local static and total air temperatures around the airfoil, and $r$ is the recovery factor, defined as the cube root of the Prandtl number.

Reynolds Number Measurement

The Reynolds number is based on the axial chord and the exit conditions:

$$
\operatorname{Re}=\frac{\mathrm{C}(\rho \mathrm{V})_{\text {exit }}}{\mu}
$$

where $\mathrm{C}$ is the chord length, $\rho$ is the fluid density, $\mathrm{V}$ is the fluid velocity, and $\mu$ is the dynamic viscosity, $(\rho \mathrm{V})_{\text {exit }}=\mathrm{W} / \mathrm{A}_{\text {exit }}$, and

$$
\mathrm{A}_{\text {exit }}=\mathrm{S} \cos \theta
$$

$\mathrm{S}$ is the blade pitch, and $\theta$ is the flow exit angle. In this paper, the flow angle is taken as equal to the camber angle $\left(61.7^{\circ}\right)$, which is approximately the case for subsonic flow. W is measured by a sharp-edged orifice downstream of the test section.

\section{Turbulence Measurements}

Turbulence intensity was measured with a TSI model 1210-20 hot film probe located 6.19 in. downstream of the turbulence grid. Flow was normal to the probe axis. The probe was calibrated in the tunnel, upstream of the turbulence grid and boundary layer bleeds, by varying the Reynolds number over the range used in this study. The probe voltage was plotted against the calculated density-velocity product, and a fourth-order, least-squares curve fit was obtained:

$$
\rho \mathrm{V}=\mathrm{B}_{0}+\mathrm{B}_{1} \mathrm{E}+\mathrm{B}_{2} \mathrm{E}^{2}+\mathrm{B}_{3} \mathrm{E}^{3}+\mathrm{B}_{4} \mathrm{E}^{4}
$$

where $\rho \mathrm{V}$ is the density-velocity product, $\mathrm{B}$ is the polynomial coefficient, and $\mathrm{E}$ is the mean voltage read from an integrating voltmeter. The turbulence intensity was then obtained from the calibration curve as 


$$
\mathrm{Tu}=\frac{\rho \mathrm{V}^{\prime}}{\rho \mathrm{V}}=\frac{\mathrm{d}[\rho \mathrm{V}(\mathrm{E})]}{\mathrm{dE}} \frac{\mathrm{dE}}{\rho \mathrm{V}(\mathrm{E})}
$$

where $\mathrm{dE}$ is taken as the root mean square of the fluctuating voltage read from a true rms meter. The turbulence intensity was measured in midchannel because it represented the location in the flow channel least affected by the airfoil leading edge and the sidewall.

\section{$\underline{\text { Results and Discussion }}$}

Figure 5 presents turbulence intensities as a function of Reynolds number for three test conditions: clear tunnel (no grid), 1/8- and 1/4-in. grids. In general, the turbulence intensities show a stronger Reynolds number dependency at lower Reynolds numbers. In all cases, the turbulence intensities decreased only slightly for Reynolds numbers greater than $3.0 \times 10^{6}$. The turbulence intensities for the clear tunnel (no grid) shown here are higher than those obtained from a typical quiescent wind tunnel because of the turbulent pipe flow condition that exists ahead of the test section. For the cases of the 1/8- and 1/4-in. bar grids, the turbulence intensities are in general agreement with those calculated from Baines and Peterson ${ }^{5}$ for Reynolds numbers greater than $3.0 \times 10^{6}$.

\section{$\underline{\text { Pressure Distribution }}$}

Both the airfoil and the contoured sidewalls were instrumented with the same number of pressure taps to check the effect of periodicity, as well as the threedimensionality, of the flow in the cascade.

Figures 6(a) and (b) show the effect of turbulence intensity on the airfoil pressure distribution at midspan at Reynolds numbers of 3.0 and $7.0 \times 10^{6}$, respectively. The turbulence levels varied from 12.3 to 1.8 percent depending on the Reynolds numbers and the turbulence grids used in these tests. The figures indicated that turbulence intensity has little or no effect on the airfoil pressure distribution. The turbulence intensity effects at other Reynolds numbers are also negligible. Similar plots for the airfoil hub and tip regions of the present experiment also show little or no turbulence intensity dependency on pressure distribution. These findings are in general agreement with Dring et al., ${ }^{6}$ who reported on the aerodynamic and heat transfer characteristics of a large-scale rotating turbine model. They found that the midspan pressure distributions were essentially unaffected by the turbulence generating grid.

Figure 7(a) compares the airfoil pressure distribution at the hub, midspan, and tip for a Reynolds number of $3.0 \times 10^{6}$ and a turbulence intensity of 6.5 percent (1/8-in. grid). The figures show that, except near the suction surface leading edge, there is no variation in the spanwise pressure distribution. This is an indication that the flow on the airfoil is mostly two-dimensional. Similar results are noted in Fig. 7(b) for a Reynolds number of $7.0 \times 10^{6}$ and a turbulence intensity of 5.9 percent.

For the 1/8-in. grid case, Figs. 8(a) to (c) compare the pressure distribution between the airfoil and the contoured sidewall at midspan for Reynolds numbers of 3.0, 5.0 , and $7.0 \times 10^{6}$. The agreement between the airfoil and the contoured sidewall is good on the pressure surface for all the Reynolds numbers shown. For the suction surface, the agreement is also good for about 50 percent of the airfoil. From about 50 percent of the chord to the trailing edge, there is deviation between the airfoil and sidewall pressure distribution. The deviation increases progressively with Reynolds number. The deviation is especially obvious at a Reynolds number of $7.0 \times 10^{6}$. It is speculated here that the reason for the deviation at the suction surface near the trailing edge is that the facility is not a true cascade. In a true cascade, the airfoil suction surface would be uncovered downstream of the throat. In this facility the continuation of the contoured sidewall pressure surface that forms the cascade wall would cause the air to continue to accelerate downstream of the throat, thereby causing the pressure to decrease. This effect is seen at all Reynolds numbers; however, it was especially pronounced at $\operatorname{Re}=7.0 \times 10^{6}$.

\section{$\underline{\text { Heat Transfer }}$}

In Fig. 9(a) the heat transfer coefficient is plotted against the normalized surface distance $\mathrm{s} / \mathrm{L}$ for Reynolds numbers of $0.75,1.5,3.0,5.0$, and $7.0 \times 10^{6}$ for the clear tunnel (no grid) case. As seen in the figure, heat transfer increases with Reynolds number, as expected. On the pressure surface, the transition (as evidenced by the sharp rise in the heat transfer coefficient) appears to occur near an $\mathrm{s} / \mathrm{L}$ of 0.09 , which is near the point of tangency of the leading edge circle. Examination of the liquid crystal photographs reveals the presence of a weak separation at this point. The pressure distribution contour also indicates a small adverse gradient near this region. It is speculated that flow separation at this point triggers the transition for the three highest Reynolds numbers; this is the reason why the transition point does not change with increasing Reynolds number. After the initial rise due to transition, the heat transfer coefficient continues to increase at a reduced rate; this is caused by the flow acceleration on the pressure surface.

On the suction surface, the location of the transition moves upstream with increasing Reynolds numbers, indicating that no flow separation is present. This is supported by the fact that the pressure distribution on the suction surface does not show any adverse pressure 
gradient and that the liquid crystal photographs do not show evidence of flow separation.

Near the suction surface trailing edge, the heat transfer coefficient for a Reynolds number of $7.0 \times 10^{6}$ shows an increasing trend, which is incompatible with the diffusion in this region shown in Fig. 8(c). The reason for this anomaly is not known at this time.

Figures 9 (b) and (c) present the heat transfer coefficients for the moderate and high turbulence cases (1/8- and 1/4-in. grids). On the pressure surface, the separation at $\mathrm{s} / \mathrm{L}=0.09$ is still present and can be seen as a small dip in the heat transfer coefficient at the two lowest Reynolds numbers. As the Reynolds number is increased, the transition moves upstream from this point. For the two highest Reynolds numbers, there is an abnormal drop in the heat transfer coefficient at the end of the transition region that corresponds to the separation point. This drop was also observed by Hippensteele, Russell, and Torres. ${ }^{4}$

In comparison with Fig. 9(a) for the clear tunnel case, heat transfer for the suction surface and at the leading edge region is higher because of the higher turbulence intensity resulting from the $1 / 8$ - and 1/4-in. grids used. Also, transition from laminar to turbulent flow occurs sooner and over shorter distances. For the same reason, heat transfer for both the pressure and suction surfaces is also higher than that for the clear tunnel case. These trends were also noted by Dring et al. ${ }^{6}$

At the leading edge, where the flow is laminar, heat transfer varies as $\mathrm{Re}^{0.5}$. A Frossling number $\left(\mathrm{Nu}_{\mathrm{d}} /\right.$ $\left(R e_{d, \text { inlet }}\right)^{0.5}$ ) plot is useful: Frossling numbers for similar turbulence levels should fall on the same curve. Figure 10(a) is a plot of the Frossling numbers at the leading edge region for the clear tunnel case. The figure shows that, with some exceptions, the Frossling numbers in the leading edge region do generally fall on a single curve. The reason why some Frossling numbers are lower is not known at this time. Figure 10(a) also shows that there is a sharp increase in heat transfer in this transition regime, especially for the higher Reynolds numbers. Aft of the leading edge region, heat transfer departs from laminar behavior and will no longer vary as the square root of the Reynolds number.

Figure 10(b) shows Frossling numbers with moderate turbulence intensity (1/8-in. grid) upstream of the vane. Frossling numbers for the leading edge region again generally fall on a single curve. Because the stagnation region heat transfer is augmented by higher freestream turbulence intensity, the level of this curve is higher than that for the lower turbulence case of Fig. 10(a). Figure 10(b) also shows that transition from laminar to turbulent flow also occurs sooner, especially for those at higher Reynolds numbers. Figure 10(c) shows Frossling numbers for high turbulence intensity (1/4-in. grid) upstream of the vane. The characteristics are similar to those of Fig. 10(b).

It would be reasonable to raise the question that, if laminar heat transfer at the leading edge with similar turbulence intensity levels can be normalized by the Frossling number, is it possible, for similar turbulence intensities, to normalize the turbulent heat transfer for the remaining airfoil surfaces? One possible approach would be to use the Nusselt number (based on the distance from the stagnation point) divided by the Reynolds number (based on the axial chord and exit conditions) raised to the 0.8 power $\left(\mathrm{Nu}_{\mathrm{s}} /\left(\mathrm{Re}_{\mathrm{c}, \text { exit }}\right)^{0.8}\right)$. Such an attempt was made using data from the 1/8-in. grid (see Fig. 11). In this figure, heat transfer values at the leading edge should be disregarded because the plotting parameter is not valid for the leading edge area. For the remaining airfoil surfaces, the figure shows a data spread of approximately \pm 6 percent on both the suction and pressure surface trailing edges. The data spread is larger near the transition region because transition occurs at different locations and over different transition lengths at different Reynolds numbers.

From the foregoing discussions, it may be concluded that, for similar turbulence intensities, heat transfer for high Reynolds numbers at the leading edge can be correlated by using the Frossling equation developed for lower Reynolds numbers. For the rest of the airfoil, heat transfer for similar turbulence intensities may be approximately correlated by using the parameter $\mathrm{Nu}_{\mathrm{s}} /\left(\mathrm{Re}_{\mathrm{c}, \text { exit }}\right)^{0.8}$.

Figure 12(a) compares the effect of turbulence intensity at Re numbers of $0.75 \times 10^{6}$ for the clear tunnel, $1 / 8$ - and 1/4-in. grid cases, respectively. The increase in stagnation region heat transfer from the clear tunnel to the $1 / 8$-in. grid (higher levels of turbulence) case is very evident. However, there seemed to be no difference between the $1 / 8$ - and $1 / 4$-in. grid cases at the leading edge region. The fact that the heat transfer coefficient for the $1 / 8$ - and the $1 / 4$-in. grid cases falls on the same curve is somewhat unexpected, considering the $1 / 8$-in. grid produces a turbulence level of about 6 percent and the 1/4-in. grid about 11 percent. The reason for this result is not known, but it could possibly be attributed to the larger turbulent length scale for the $1 / 4$-in. grid. The heat transfer coefficient in the stagnation region is proportional to the turbulence intensity, and it has been shown to be inversely proportional to the ratio of the length scale to the leading edge diameter (G. James VanFossen and Chan Y. Ching, "Measurement of the Influence of Turbulence Integral Length Scales on Stagnation Region Heat Transfer, ${ }^{n}$ to be published in 1993, 
NASA Lewis Research Center, Cleveland, Ohio). The figure also shows that higher turbulence levels move transition further upstream.

Figure 12(b) compares the effect of turbulence intensity at $\operatorname{Re}=7.0 \times 10^{6}$. At this high Reynolds number, the transition point has moved upstream almost to the stagnation point. The heat transfer coefficients for the 1/8-in. grid are still higher than those for the clear tunnel (no grid), but the heat transfer coefficients for the 1/8- and the 1/4-in. grid cases are no longer coincident in the stagnation region; the 1/4-in. grid has the highest heat transfer coefficients there.

In Fig. 13 the Frossling number at the stagnation point is plotted against a parameter developed by VanFossen and Ching. This parameter involves turbulence intensity, Reynolds number, and integral length scale. The solid curve is their correlation and the dashed curve is a \pm 8 -percent error band. Length scales for the present data were estimated from VanFossen and Ching's curve fit of the length scale versus the distance; they used 1/2-, 1/4-, 1/8-, and 1/16-in. grids which had the same ratio of bar width to mesh spacing as that of the present test. For the data with clear tunnels (no grid), the length scale was set to the width of the test section, 8.5 in. Agreement with the correlation is reasonable especially at the high Reynolds numbers for the two turbulence grids. Agreement for the clear tunnel case is not quite as good but is still reasonable considering the greater uncertainty in the length scale used.

Figure 14 compares the pressure distributions of the airfoil and the contoured sidewall at $\operatorname{Re}=7.0 \times 10^{6}$ with the computed pressure distribution from TRAFC2D superimposed. The predicted values agree well with the contoured sidewall experimental data, except that near the suction surface leading edge area. The small disagreement on the suction surface leading edge area is probably caused by the three-dimensional effect. Because the code used was a two-dimensional version, it was not able to follow the three-dimensional pressure distribution. The agreement is good for the rest of the sidewall surface. Agreement is generally good with the experimental pressure distribution on the airfoil, except in certain areas: near the suction surface leading edge, there is again the possible three-dimensional flow field effect, as just discussed; near the suction surface trailing edge area, the airfoil pressure was decreased because of the presence of the contoured sidewall (see the earlier discussion in the Pressure Distribution section).

A comparison of the predicted and experimental heat transfer coefficients is presented in Fig. 15 for Reynolds numbers of $1.5,3.0$, and $7.0 \times 10^{6}$ for the clear tunnel case. The predictive tool used was again
TRAFC2D. As can be seen from the figure, the heat transfer coefficients on the suction surface are relatively well predicted. On the pressure surface, the heat transfer coefficients are underpredicted for all the Reynolds numbers. The predicted heat transfer values show encouraging results; however, it is evident that additional work on the predictive techniques is required.

\section{Uncertainty Analysis}

An uncertainty analysis, based on the work of Abernathy and Benedict ${ }^{7}$ showed that the uncertainty is a function of Reynolds numbers. For all Reynolds numbers and all turbulence levels tested in this facility, a conservative estimate of the uncertainty of the heat transfer coefficients is approximately 6 percent, with the exception of two cases $\left(\operatorname{Re}=3.0\right.$ and $5.0 \times 10^{6}$, for the clear tunnel). The uncertainty of the heat transfer coefficients for these two worst cases is 11 and 8.7 percent, respectively. The high uncertainty level of these two cases is attributed to the extremely warm air temperature in these tests $\left(91^{\circ} \mathrm{F}\right)$, resulting in a temperature difference of only $10^{\circ} \mathrm{F}$ between the air and the liquid crystal.

\section{$\underline{\text { Conclusions }}$}

Aerodynamic and heat transfer data were presented for Reynolds numbers ranging from 0.75 to $7.0 \times 10^{6}$ and turbulence intensities ranging from 1.8 to 15.1 percent. The range of Reynolds numbers encompassed those encountered in current aeropropulsion turbines and in the Space Shuttle main engine (SSME) turbopump turbines.

From the pressure distribution plots presented, it can be concluded that

1. The flow in the cascade was nonperiodic at the airfoil suction surface near the trailing edge. This nonperiodicity was evident in all Reynolds numbers although it was not very pronounced except at $R e$ $=7.0 \times 10^{6}$.

2. The flow over the airfoil was primarily twodimensional.

3. The turbulence intensity had a minimal effect on the pressure distribution, as expected.

4. A numerical solution using the TRAFC2D code for pressure distribution agreed well with the contoured sidewall data.

With respect to heat transfer, the results of this study indicated that 
1. Reynolds number had a large effect on heat transfer and on the transition from laminar to turbulent flow.

2. For the high Reynolds numbers typical of the Space Shuttle main engine turbopump, heat transfer was dominated by transitional and turbulent flow downstream of the stagnation region.

3. For a given turbulence intensity level, heat transfer at the leading edge for all Reynolds numbers can be correlated with the Frossling number developed for lower Reynolds numbers.

4. For a given turbulence intensity, heat transfer on the airfoil downstream of the leading edge can be approximately correlated by using a dimensionless parameter (Nusselt number, based on the distance from the stagnation point, divided by the Reynolds number, based on the axial chord and exit conditions, raised to the 0.8 power) to within \pm 6 percent at the trailing edge.

5. A comparison of the experimental heat transfer data with the numerical solution of the TRAFC2D code showed encouraging results.

\section{References}

1. Schobeiri, T., McFarland, E.R., and Yeh, F.C., "Aerodynamic and Heat Transfer Investigations on a High Reynolds Number Turbine Cascade," ASME Paper 91-GT-157. (Also, NASA TM-103260, 1991.)

2. Ameri, A.A., and Arnone, A., "Navier-Stokes Turbine Heat Transfer Predictions Using Two Equa- tion Turbulence Closures," AIAA Paper 92-3067, 1992.

3. Hippensteele, S.A., Russell, L.M., and Stepka, F.S., "Evaluation of a Method for Heat Transfer Measurements and Thermal Visualization Using a Composite of a Heater Element and Liquid Crystals," Journal of Heat Transfer, Vol. 105, No. 1, Feb. 1983, pp. 184-189. (Also, NASA TM-81639, 1981.)

4. Hippensteele, S.A., Russell, L.M., and Torres, F.J., "Use of a Liquid-Crystal, Heater Element Composite for Quantitative, High Resolution Heat Transfer Coefficients on a Turbine Airfoil, Including Turbulence and Surface Roughness Effects," Pressure Temperature Measurements, edited by J.H. Kim and R.J. Moffat, ASME, New York, 1987, pp. 105-120. (Also, NASA TM-87355, 1987.)

5. Baines, W.D., and Peterson, E.G., "An Investigation of Flow Through Screens," Transactions of the ASME, Vol. 72, July 1951, pp. 468-480.

6. Dring, R.P., Blair, M.F., Joslyn, H.D., Power, G.D., and Verdon, J.M., "The Effects of Inlet Turbulence and Rotor/Stator Interactions on the Aerodynamics and Heat Transfer of a LargeScale Rotating Turbine Model," Vol. 1, NASA CR-4079, May 1986.

7. Abernathy, R.B., and Benedict, R.P., Measurement Uncertainty: A Standard Methodology, ISA, Research Triangle Park, NC, 1984. 


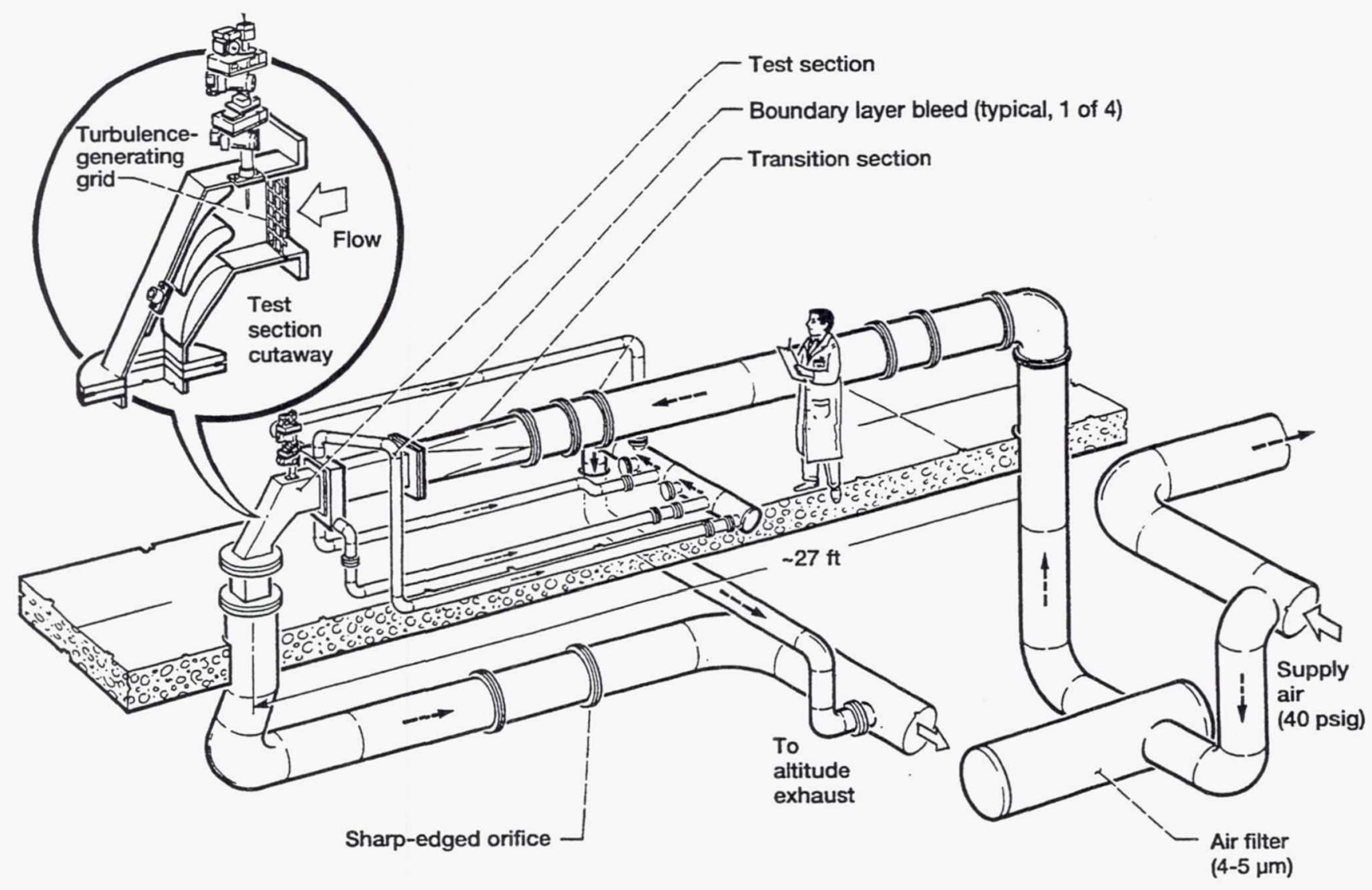

Figure 1.-Variable Reynolds Number Heat Transfer Facility.

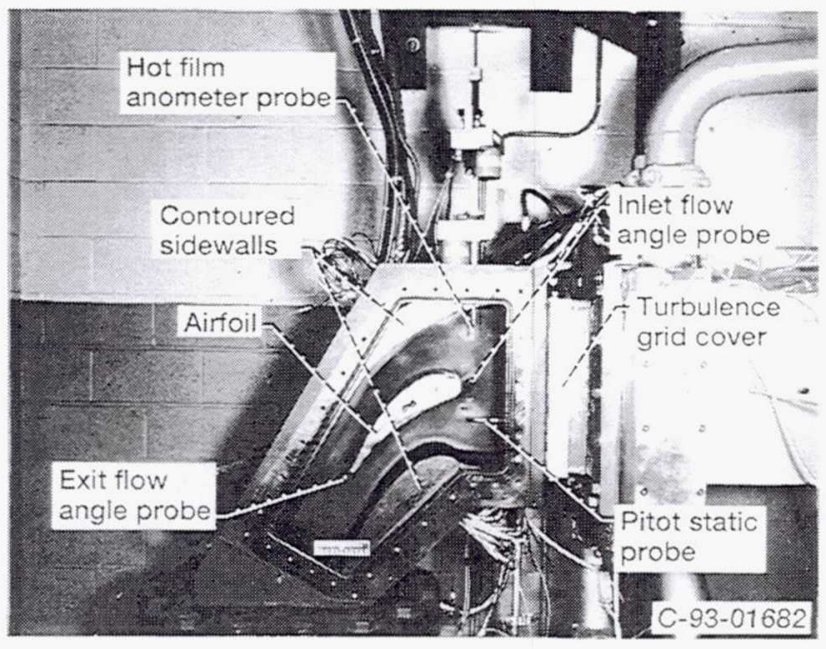

Figure 2.-Test section.

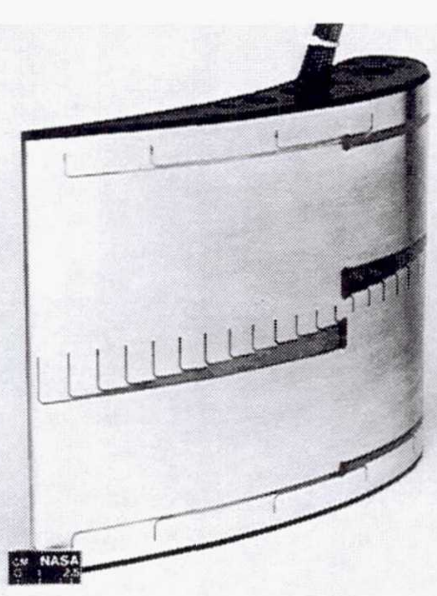

C- $88-11421$

Figure 3.-Pressure distribution airfoil showing pressure tap locations on suction surface. 


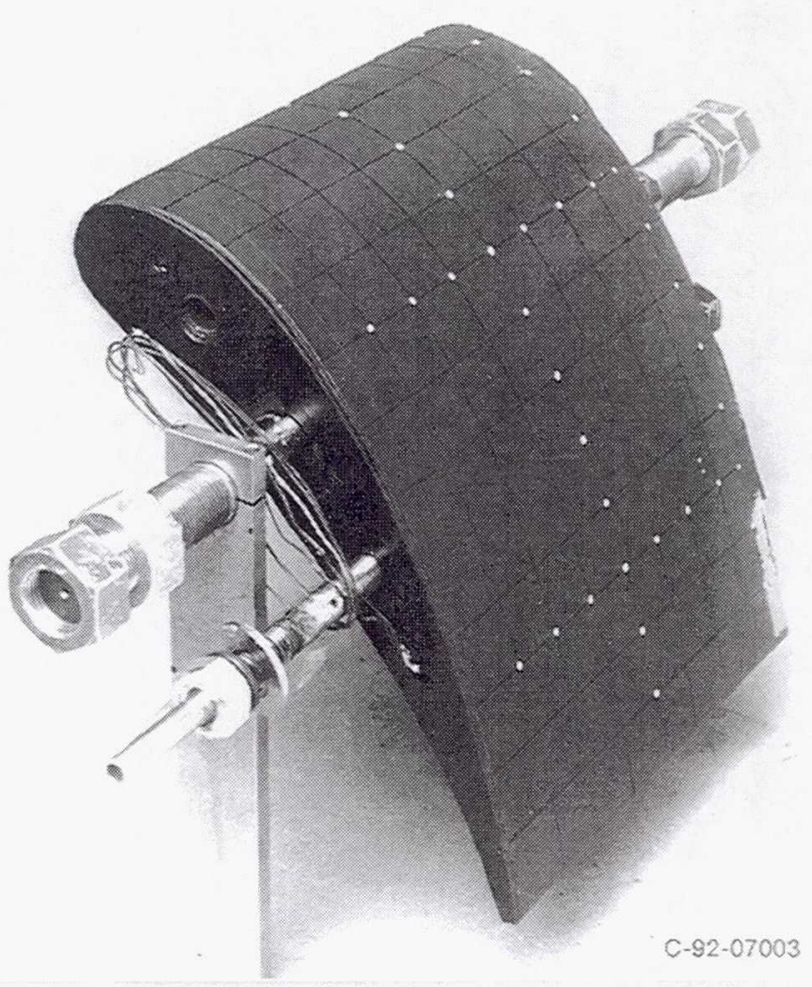

Figure 4.- Heat transfer airfoil showing grid markings for the locations of temperature distribution.

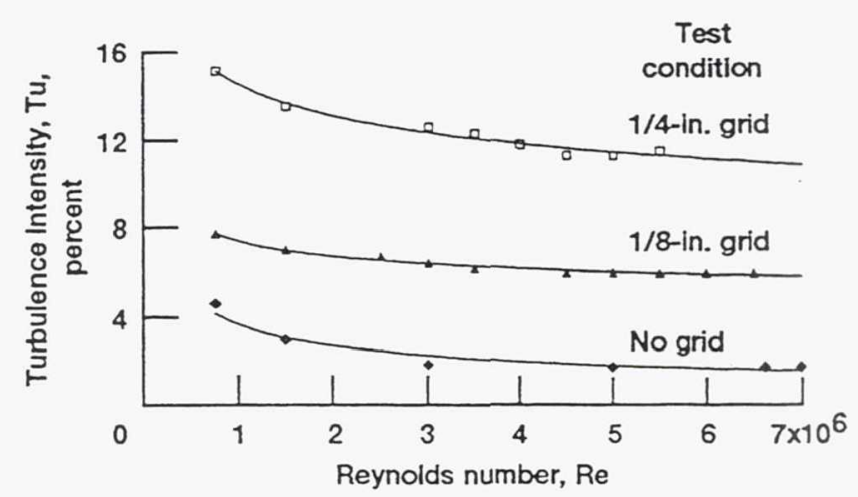

Figure 5.-Turbulence intensity as function of Reynolds number for three test conditions. 


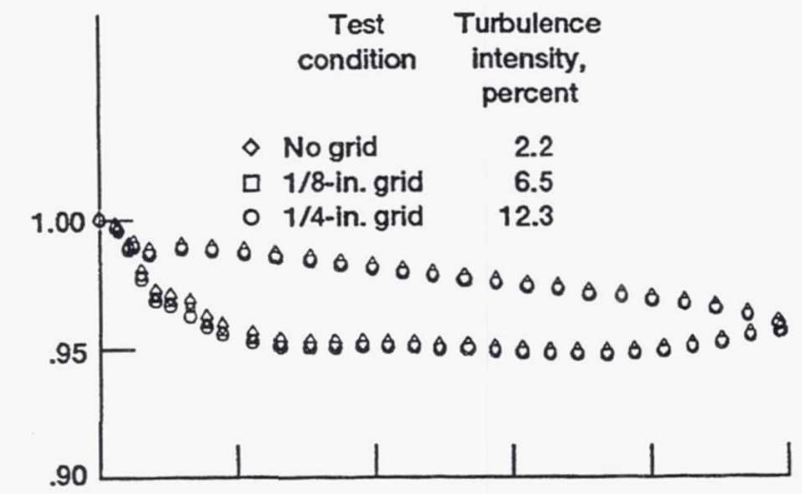

(a) Reynolds number, Re, $3.0 \times 10^{6}$.

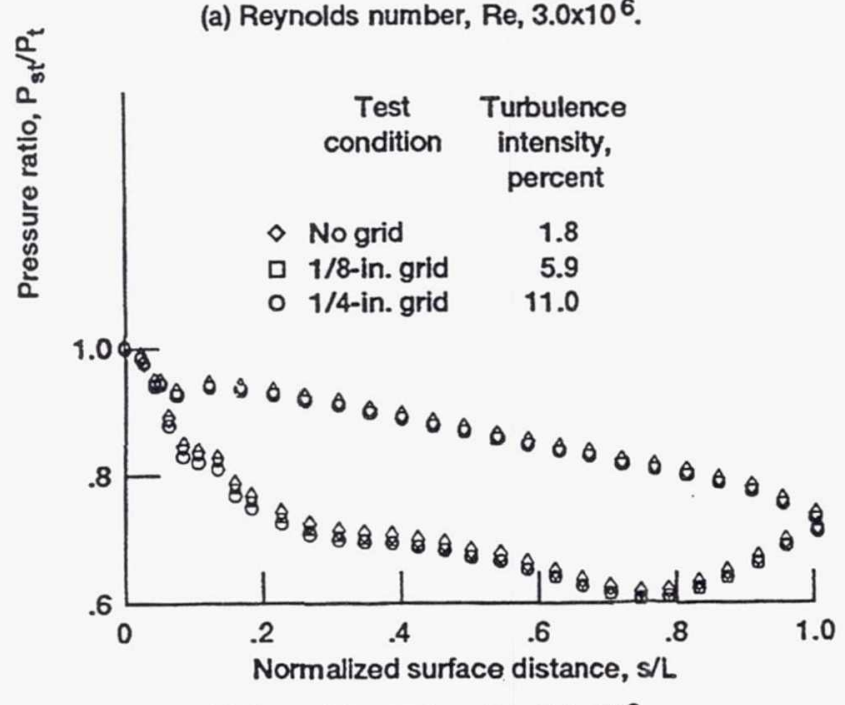

(b) Reynolds number, Re, $7.0 \times 10^{6}$.

Figure 6.-Effect of turbulence intensity on airfoil pressure distribution at midspan.

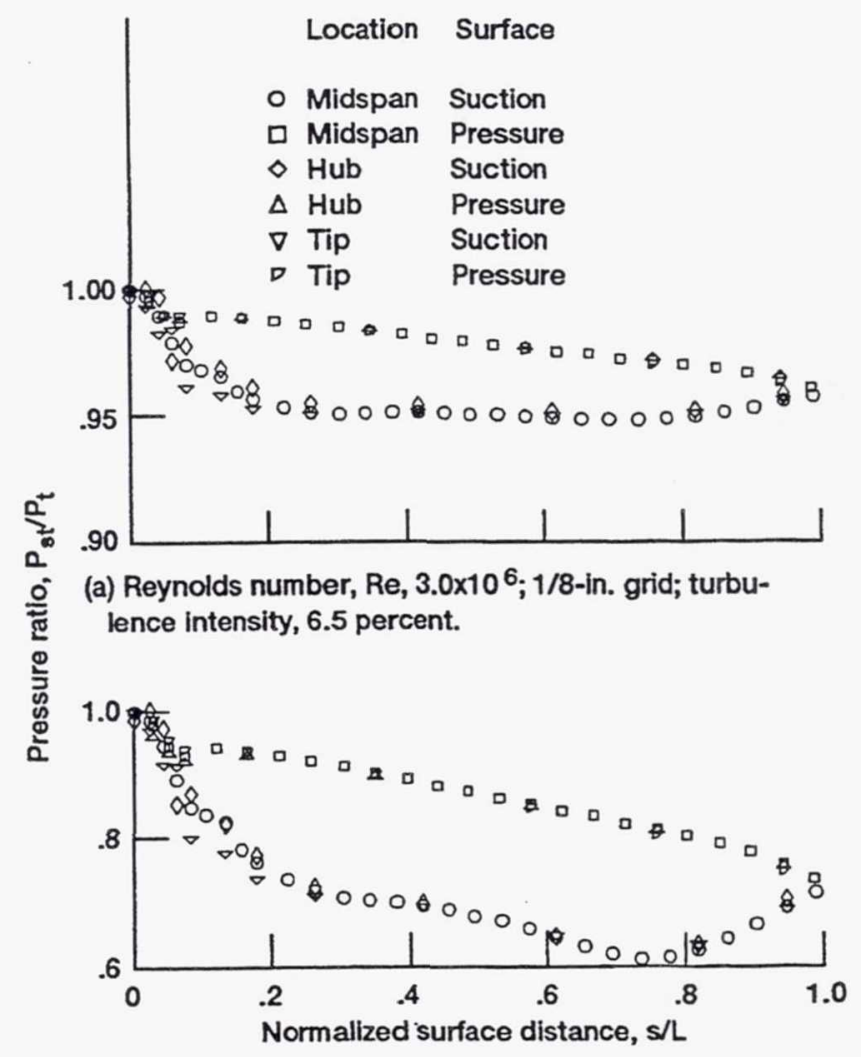

(b) Reynolds number, Re, $7.0 \times 10^{6} ; 1 / 8$-in. grid; turbulence intensity, 5.9 percent.

Figure 7.-Airfoil pressure distribution at midspan, hub and tip. 


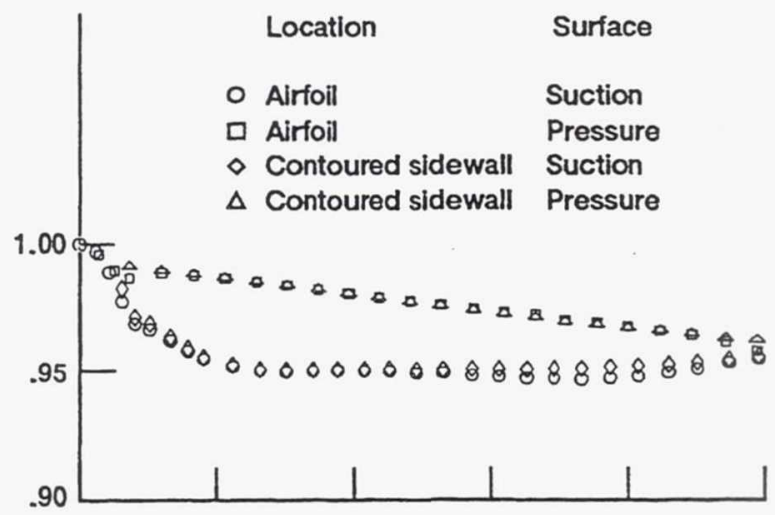

(a) Reynolds number, Re, $3.0 \times 10^{6}$; turbulence intensity, 6.5 percent.

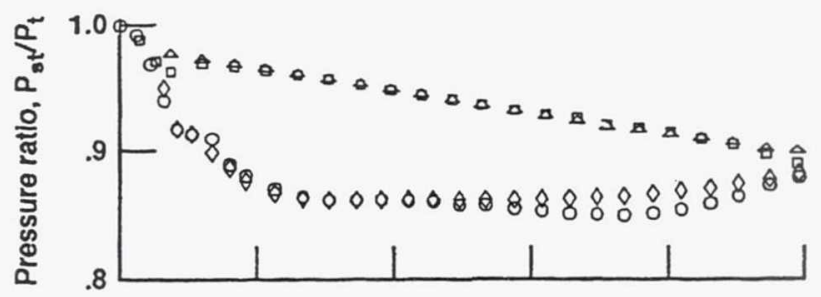

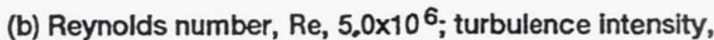
6.1 percent.

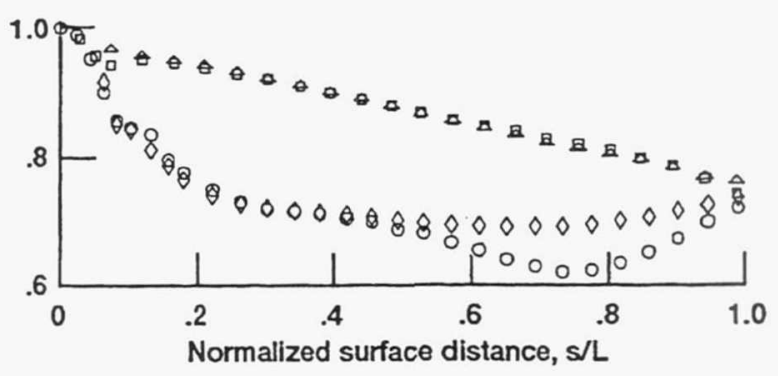

(c) Reynolds number, Re, $7.0 \times 10^{6}$; turbulence intensity, 5.9 percent.

Figure 8.-Comparision of airfoil and contoured sidewall pressure distribution at midspan for $1 / 8$-in. grid. 

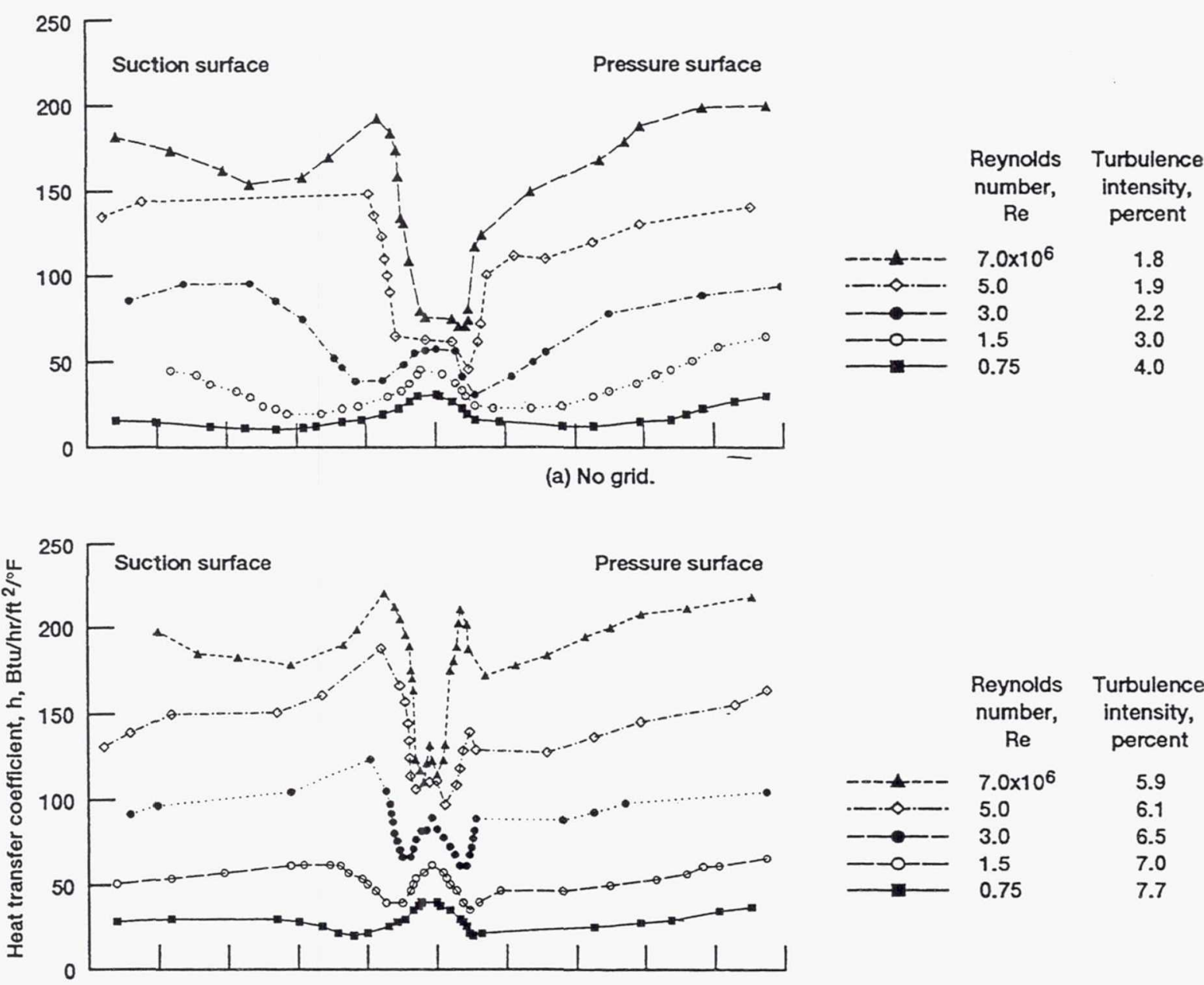

Reynolds Turbulence number, intensity, Re percent

(b) 1/8-in. grid.

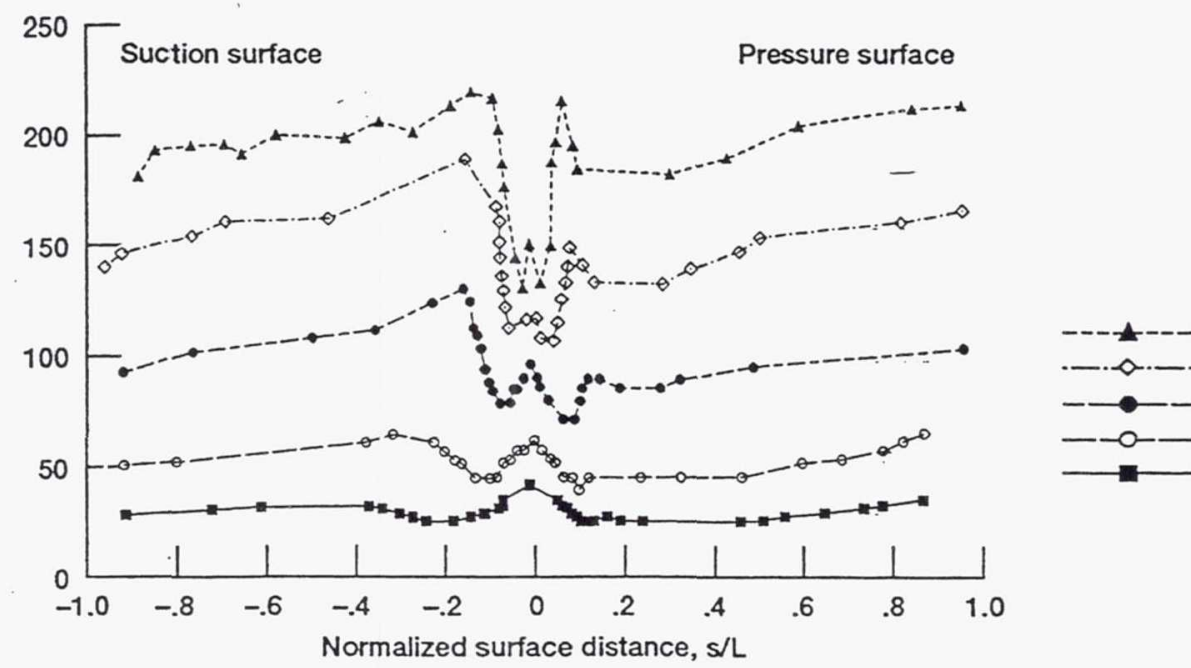

Reynolds Turbulence number, intensity,

Re percent

$7.0 \times 10^{6} \quad 11.0$

$5.0 \quad 11.5$

3.0

0.75

15.1

(c) 1/4-in. grid.

Figure 9.-Effect of Reynolds number on heat transfer coefficient. 

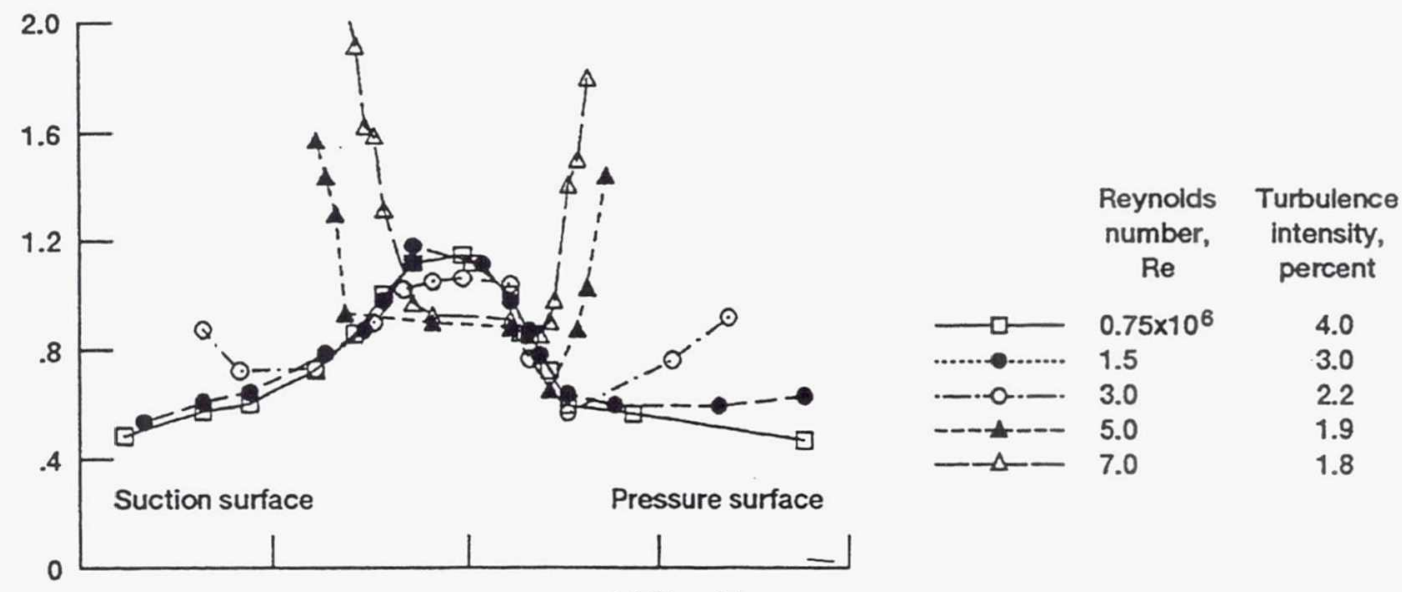

(a) No grid.
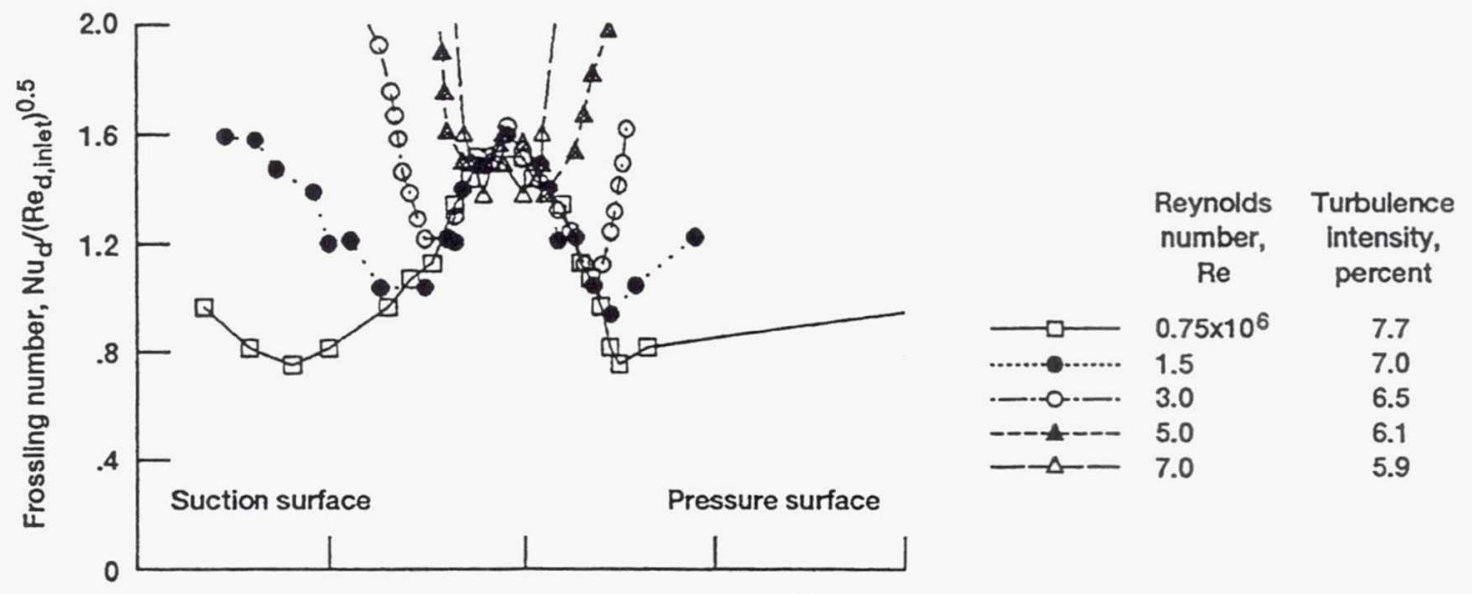

(b) 1/8-in. grid.

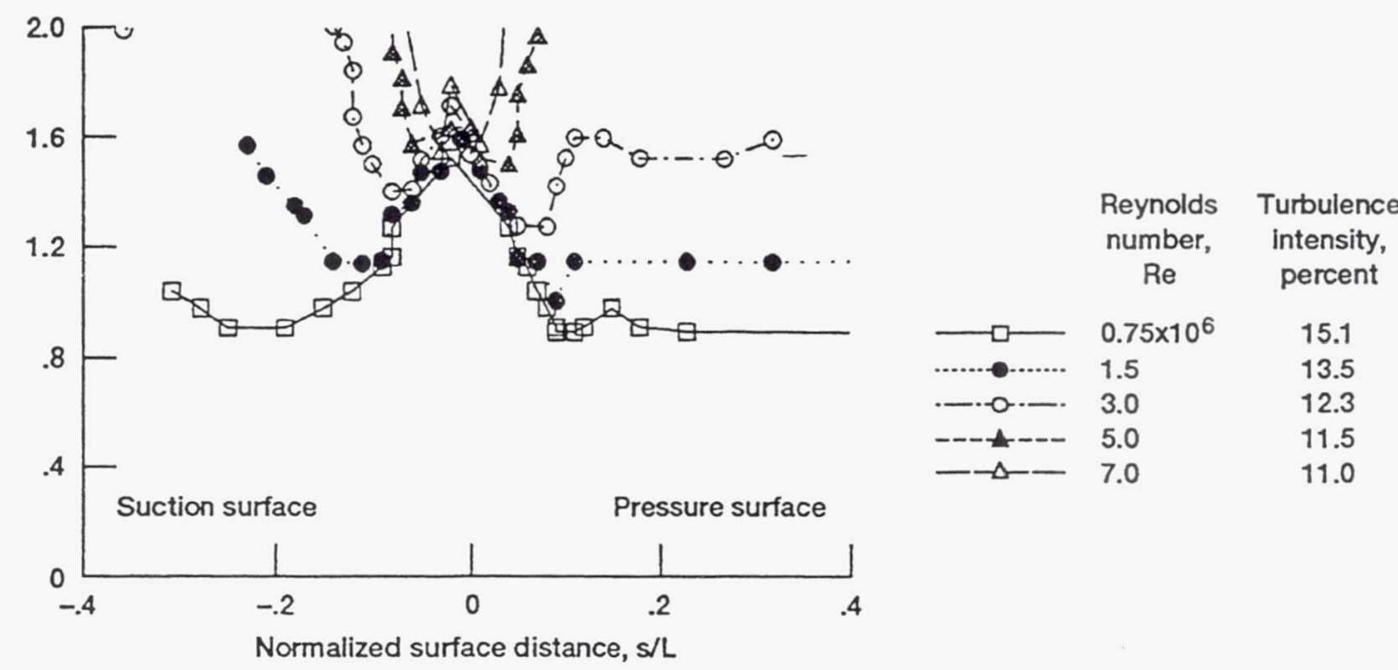

(c) 1/4-in. grid.

Figure 10.-Frossling correlation of variable Reynolds number heat transfer data at leading edge. 


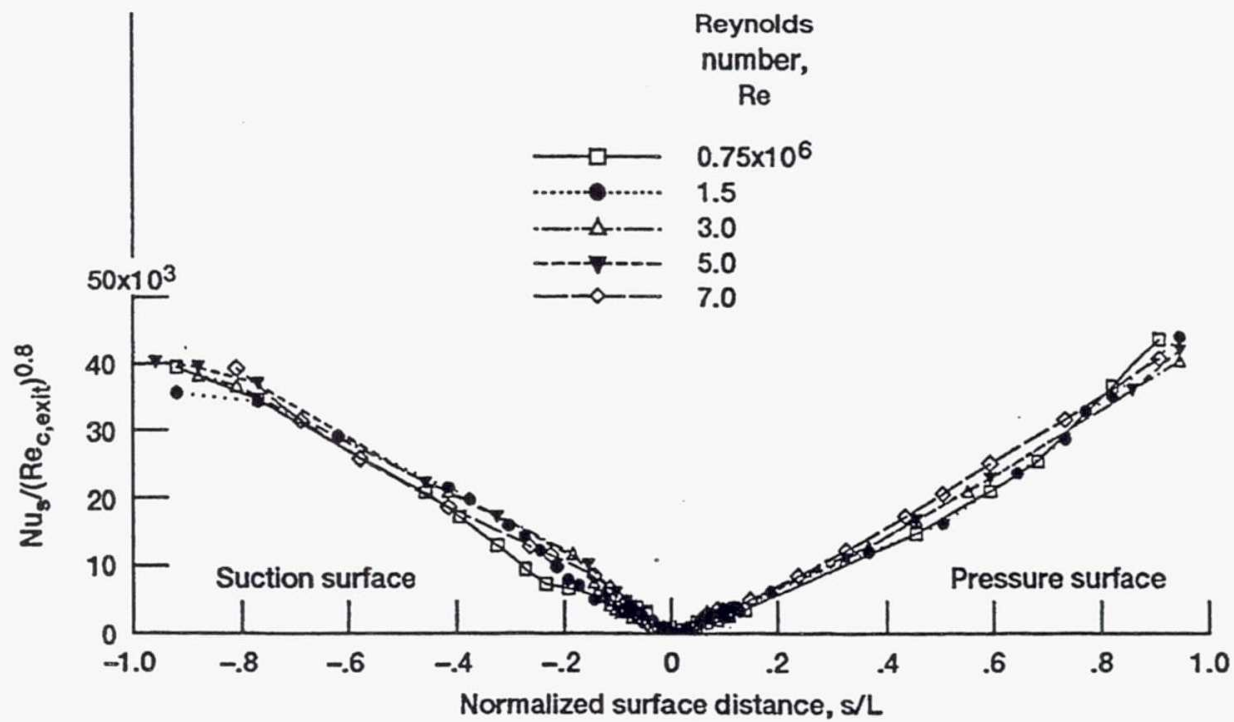

Figure 11.-Correlation of variable Reynolds number heat transfer data for $1 / 8$-in. grid case.

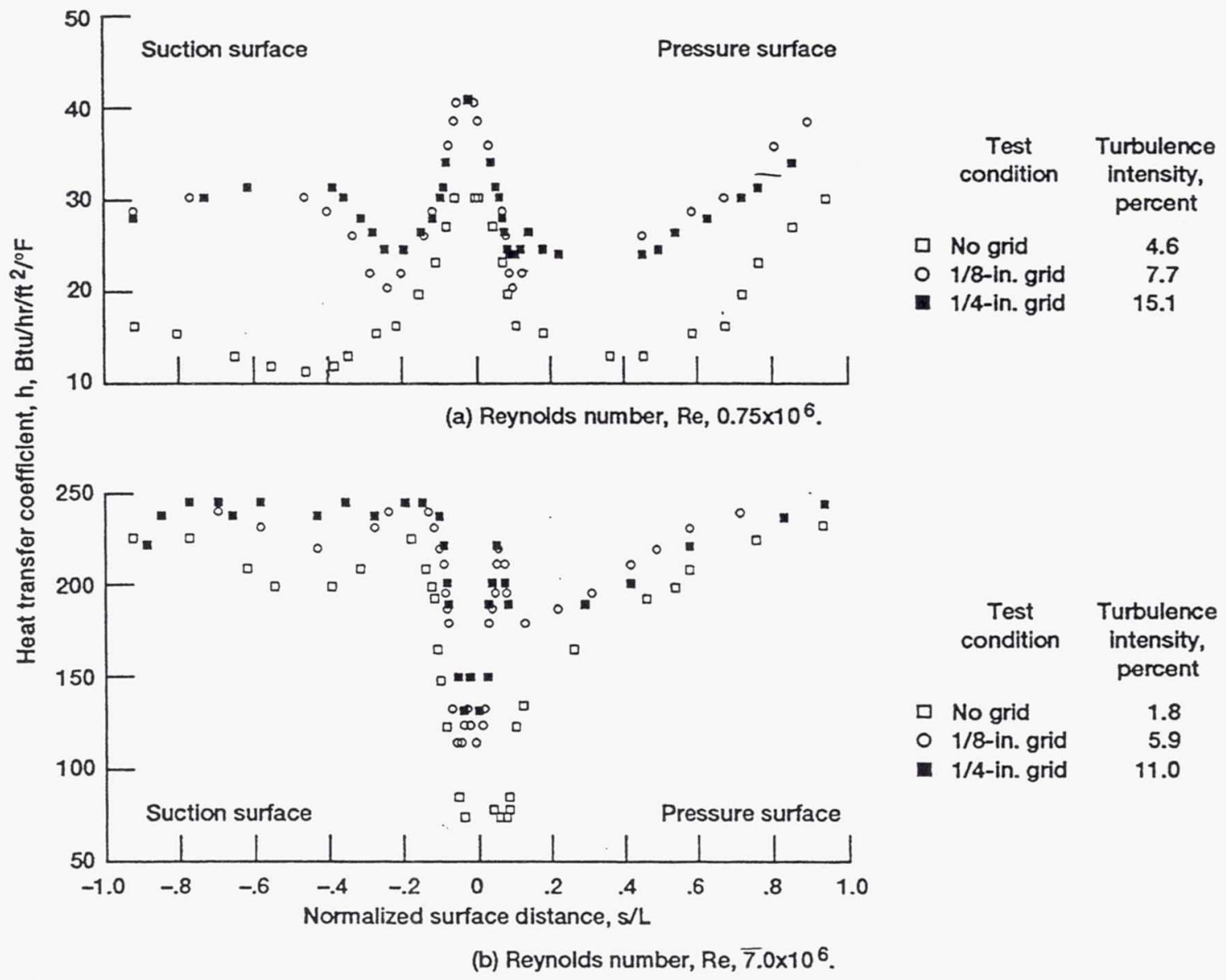

Figure 12.-Effect of turbulence intensity on heat transfer coefficient. 


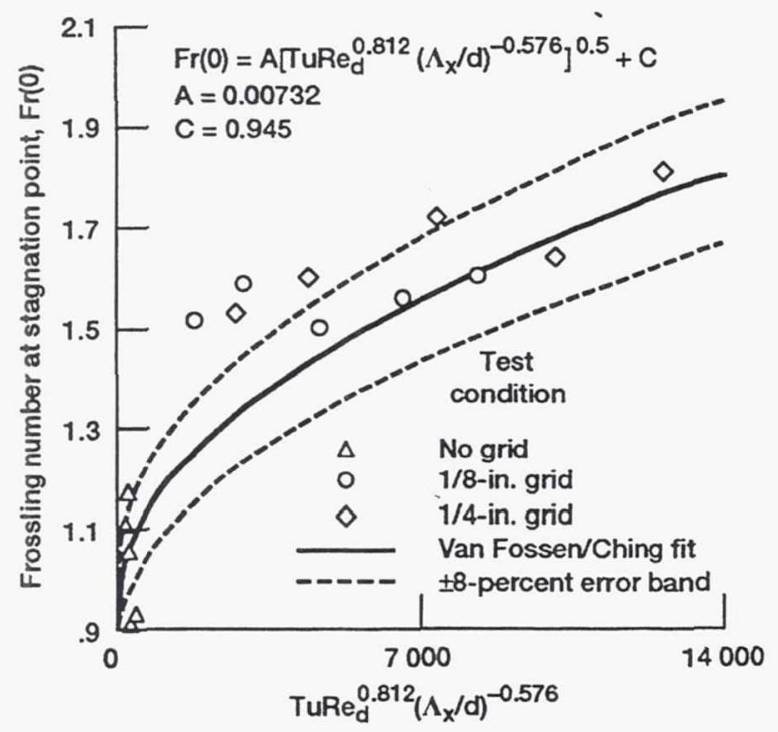

Figure 13.- Heat transfer at stagnation point.

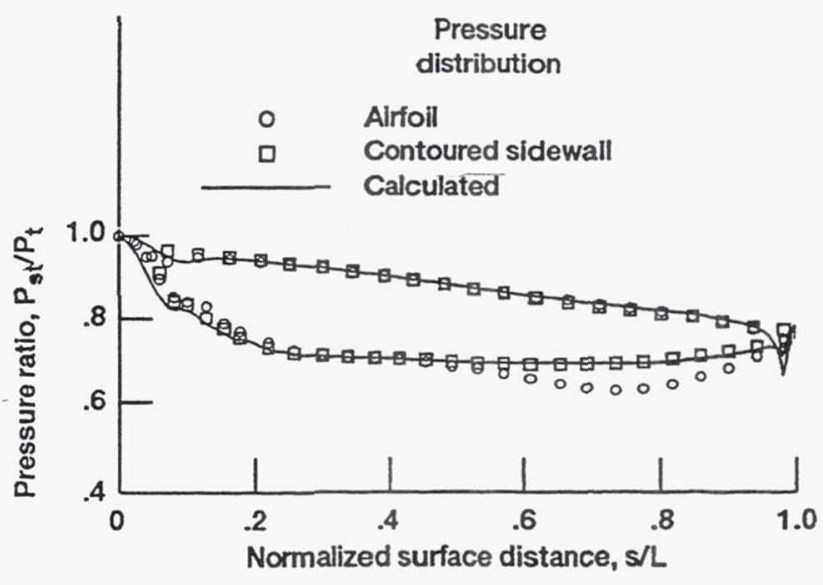

Figure 14.-Comparison of computed and experimental pressure distributions of airfoil and contoured sidewall at Reynolds number of $7.0 \times 10^{6}$.

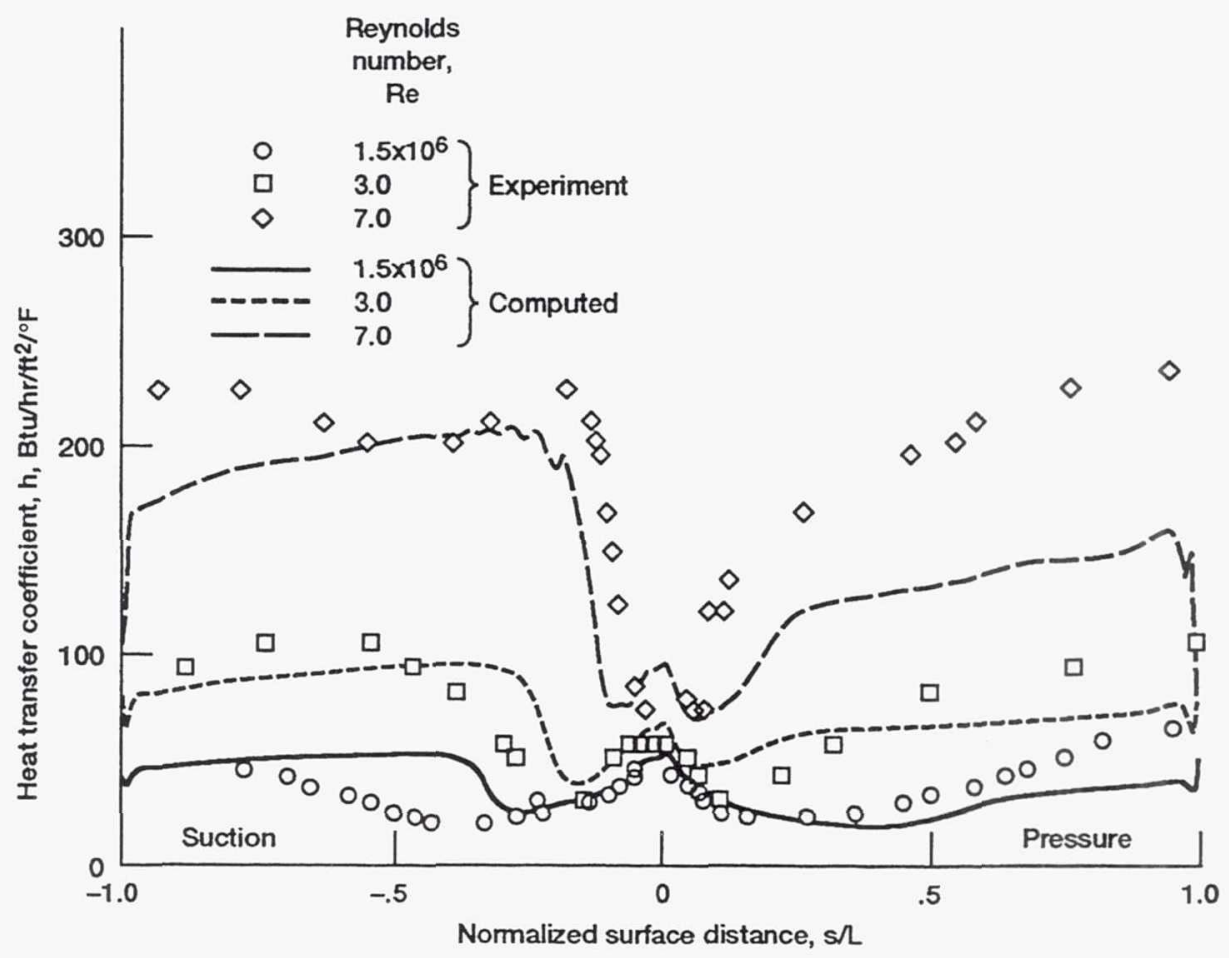

Figure 15.-Comparison of computed and experimental airfoil heat transfer coefficients for clear tunnel (no grid) condition. 


\section{REPORT DOCUMENTATION PAGE}

Public reporting burden for this collection of information is estimated to average 1 hour per response, including the time for reviewing instructions, searching existing data sources, gathering and maintaining the data needed, and completing and reviewing the collection of information. Send comments regarding this burden estimate or any other aspect of this collection of information, including suggestions for reducing this burden, to Washington Headquarters Services, Directorate for Information Operations and Reports, 1215 Jefferson Davis Highway, Suite 1204, Arlington, VA 22202-4302, and to the Office of Management and Budget, Paperwork Reduction Project (0704-0188), Washington, DC 20503.

\begin{tabular}{|l|c|c|}
\hline 1. AGENCY USE ONLY (Leave blank) & $\begin{array}{c}\text { 2. REPORT DATE } \\
\text { June } 1993\end{array}$ & $\begin{array}{r}\text { 3. REPORT TYPE AND DATES COVERED } \\
\text { Technical Memorandum }\end{array}$ \\
\hline
\end{tabular}

\section{TITLE AND SUBTITLE}

5. FUNDING NUMBERS

High Reynolds Number and Turbulence Effects on Aerodynamics and Heat

Transfer in a Turbine Cascade

6. AUTHOR(S)

WU-505-62-52

Frederick C. Yeh, Steven A. Hippensteele, G. James Van Fossen, Philip E. Poinsatte, and Ali Ameri

7. PERFORMING ORGANIZATION NAME(S) AND ADDRESS(ES)

National Aeronautics and Space Administration

Lewis Research Center

Cleveland, Ohio 44135-3191

8. PERFORMING ORgANIZATION REPORT NUMBER

E-7791

9. SPONSORING/MONITORING AGENCY NAME(S) AND ADDRESS(ES)

10. SPONSORING/MONITORING AGENCY REPORT NUMBER

National Aeronautics and Space Administration

Washington, D.C. 20546-0001

NASA TM-106187

AIAA-93-2252

\section{SUPPLEMENTARY NOTES}

Prepared for the 29th Joint Propulsion Conference and Exhibit cosponsored by the AIAA, SAE, ASME, and ASEE, Monterey, California, June 28-30, 1993. Frederick C. Yeh, Steven A. Hippensteele, G. James Van Fossen, and Philip E. Poinsatte, NASA Lewis Research Center. Ali Ameri, NASA Research Associate, University of Kansas, Center for Research, Inc., Lawrence, Kansas 66044. Responsible person, Frederick C. Yeh, (216) $433-5872$.

12a. DISTRIBUTION/AVAILABILITY STATEMENT

12b. DISTRIBUTION CODE

Unclassified - Unlimited

Subject Category 34

13. ABSTRACT (Maximum 200 words)

Experimental data on pressure distribution and heat transfer on a turbine airfoil were obtained over a range of Reynolds numbers from 0.75 to $7.5 \times 10^{6}$ and a range of turbulence intensities from 1.8 to about 15 percent. The purpose of this study was to obtain fundamental heat transfer and pressure distribution data over a wide range of high Reynolds numbers and to extend the heat transfer data base to include the range of Reynolds numbers encountered in the Space Shuttle main engine (SSME) turbopump turbines. Specifically, the study aimed to determine (1) the effect of Reynolds number on heat transfer, (2) the effect of upstream turbulence on heat transfer and pressure distribution, and (3) the relationship between heat transfer at high Reynolds numbers and the current data base. The results of this study indicated that Reynolds number and turbulence intensity have a large effect on both the transition from laminar to turbulent flow and the resulting heat transfer. For a given turbulence intensity, heat transfer for all Reynolds numbers at the leading edge can be correlated with the Frossling number developed for lower Reynolds numbers. For a given turbulence intensity, heat transfer for the airfoil surfaces downstream of the leading edge can be approximately correlated with a dimensionless parameter. Comparison of the experimental results were also made with a numerical solution from a two-dimensional Navier-Stokes code.

\section{SUBJECT TERMS}

Heat transfer; Pressure distribution; High Reynolds number

\begin{tabular}{|c|c|}
\hline $\begin{array}{c}\text { 17. SECURITY CLASSIFICATION } \\
\text { OF REPORT } \\
\text { Unclassified }\end{array}$ & $\begin{array}{c}\text { 18. SECURITY CLASSIFICATION } \\
\text { OF THIS PAGE } \\
\text { Unclassified }\end{array}$ \\
\hline
\end{tabular}
19. SECURTYY CLASSIFICATION OF ABSTRACT Unclassified 
National Aeronautics and

Space Administration

Lewis Research Center

Cleveland, Ohio 44135

Omcial Businese

Penatty for Prtvate Uea $\$ 200$
FOURTH CLASS MAIL

\section{ADDRESS CORRECTION REQUESTED}

